\title{
Crime and unemployment in Greece: Evidence before and during the crisis
}

\author{
Ioannis Laliotis* \\ School of Economics, University of Surrey, UK
}

Received: 22 August 2015

Revised: 4 January 2016

Accepted: 31 January 2016

\begin{abstract}
This paper explores the relationship between unemployment and crime in Greece before and during the crisis using panel data at the regional level for the period 1999-2013. The results indicate the operation of a positive relationship between specific crime categories and male unemployment only during the crisis, a weaker effect of long term unemployment only on the total criminal activity and they reveal the existence of significant dynamics.
\end{abstract}

Keywords: crime; unemployment; crisis; Greece

JEL Classification Codes: J60, K40

\section{Introduction}

The relationship between unemployment and crime (U-C hereafter) has received a lot of empirical investigation. Freeman (1999) argued that their association is rather weak and its direction and magnitude depend on the level of aggregation and the model specification. Several studies have presented evidence supporting the existence of a positive and statistically significant relationship between the two variables (e.g. Carmichael and Ward, 2001; Raphael and Winter-Ebmer, 2001), while others fail to do so after controlling for regional fixed effects (Machin and Meghir, 2004). Standard microeconomic theory suggests that the opportunity cost of crime is a negative function of the unemployment rate, predicting a positive relationship driven by a motivational effect (Becker, 1968). However, a negative relationship due to an opportunity effect has also been supported by later research (Cantor and Land, 1985). More recent papers from the sociological literature have provided empirical support for both the effects (Arvanites and Defina, 2006; Phillips and Land, 2012), however, the mediating role of opportunity is subject to ongoing research (e.g. Kleck and Chiricos, 2002).

\footnotetext{
*E-mail: i.laliotis@surrey.ac.uk.
}

Citation: Laliotis, I. (2016) Crime and unemployment in Greece: Evidence before and during the crisis, Economics and Business Letters, 5(1), 10-16. 
This paper attempts a first investigation of the U-C relationship using Greek regional data from the period before and during the ongoing sovereign debt crisis which is accompanied by a dramatic increase of the unemployment rate. In a recent paper, Saridakis and Spengler (2012) reported a positive U-C relationship in Greece for the period 1991-1998 but without using officially published data. The authors argued that their results would be insightful regarding the consequences of the ongoing sovereign debt crisis which is accompanied by the deterioration of the labour market conditions and the decline in the clear-up rates driven by the budget cuts in law enforcement. This study provides empirical evidence to answer those concerns focusing on the male unemployment rate as it has been argued that the operating motivational effect for this group can be stronger (Carmichael and Ward, 2001). The effect of long-term unemployment is examined as well because it can also be positively associated with criminal activity at the regional level and its implications have received much less empirical investigation (Maching and Manning, 1999). Using panel data at the regional level covering the period 1999-2013 and applying relevant estimation techniques in order to address the issue of endogeneity, the estimated results support a positive linkage between specific types of criminal activity and the male unemployment rate only after 2009. Also, a negative relationship between labour market conditions and crimes against life is uncovered during the crisis. Moreover, criminal activity exhibits a significant degree of persistence over time in most of the cases examined.

The remainder of this paper is organized as follows. Section 2 outlines the methods used in order to explore the main working hypothesis. Section 3 makes a brief presentation of the data used in the empirical analysis. Section 4 presents the obtained results and Section 5 concludes.

\section{Methods}

The U-C relationship is investigated by regressing the logarithms of the reported crime rates per 100,000 inhabitants on male and long-run unemployment separately, a lagged dependent variable in order to control for dynamics, a set of some other standard demographic explanatory variables, region and year fixed effects and a region-specific time trends. In its general form, the estimated model is of the following form:

$$
\text { Crime }_{r t}=\beta_{o}+\beta_{1} \text { Crime }_{r t-1}+\beta_{2} U_{r t}+\beta_{3} X_{r t}+\delta_{r}+\lambda_{t}+\varphi_{r} \text { time }_{t}+\epsilon_{r t}
$$

where Crime $_{r t}$ is the log of the crime rate in the $r$-th region during the $t$-th year. The measures of crime activity considered in this paper are the total crime rate, crimes against life, against property, against personal freedom and crimes related to drugs. It should be noticed that crimes against property include both robberies and thefts which are usually examined separately, however, no further disaggregation was possible with the available data. $U_{r t}$ denotes the regional unemployment rate, either for males or the long-term one, in a given year. Apart from controlling for the unemployment rate, the explanatory vector $X_{r t}$ includes several economic and demographic variables, namely the share of individuals between 15 and 39 years old, the population density (thousands per square kilometre) that serves as an urbanization index, the share of individuals who attended only primary schooling, the share of foreigners and the ratio of the 90th to the 10th decile of the gross hourly wage distribution as an inequality proxy which is typically being used in the relevant literature (e.g. Witt et al., 1998). In order to avoid any mechanical association with the business cycle, individual wages have been corrected for composition effects via the estimation of a standard Mincer wage generating function. All these explanatory variables are expressed in logarithms and capture time-varying regional heterogeneity. A post-2009 binary indicator and its interaction with the unemployment rate test for a possible differentiation of the U-C relationship during the economic downturn. Year fixed 
effects $\left(\lambda_{t}\right)$ capture common time effects across regions, while $\delta_{r}$ and $\epsilon_{r t}$ denote the regionspecific and the idiosyncratic components of the error term which are assumed to be independently distributed across regions. Therefore, the relationship between unemployment on crime is estimated through within-region deviations from aggregate trends. A region-specific linear time trend $\left(\right.$ time $\left._{t}\right)$ has also been included in the model in order to control for systematic regional pressure on criminal activity caused from unobserved factors. Finally, the inclusion of a lagged dependent variable controls for inertia in regional criminal activity. Unfortunately, no controls for detection risk, punishment effects or police resources were available. Such variables have been used in previous studies and they have been found to reduce criminal activity and they can also be related to the unemployment level. Especially during recessions any reductions in police funding may decrease the arrest rate and affect criminal activity, hence the omission of deterrence-related variables may cause a bias in the estimates. However, the region and time fixed effects should adequately absorb such influences from omitted variables that evolve similarly over time across regions or remain fixed over time but vary across regions (Öster and Agell, 2007). Moreover, the regional time trend should capture a part of the withinregion crime rate variation caused by region-specific factors, hence the adoption of a quite flexible model specification will mitigate any bias caused from unobserved heterogeneity (Raphael and Winter-Ebmer, 2001).

Estimating Eq. 1 using OLS would lead to biased estimates because some of the explanatory variables, especially the unemployment rate, may be endogenous, therefore the interpretation of the U-C relationship would be empirically difficult because causation may run in both directions. Applying the Within (or Least Squares Dummy Variable, LSDV) estimator is a good starting point because it addresses the problem arising from the correlation between the explanatory variables and the region-specific component of the disturbance term. However, given the relatively short time dimension of the panel the results would suffer from a dynamic panel bias of order $1 / T$ and the explanatory variables would still be considered as strictly exogenous, while a plausible assumption is that they are correlated with present and past shocks in the crime equation. Another concern is about the endogeneity of the lagged dependent variable that is not tackled using the Within estimator, while instrumenting it with its own past realizations would result in losing degrees of freedom and the results would still be suffering from dynamic panel bias.

Several studies exploring the U-C relationship use instrumental variables techniques in order to address the endogeneity of the unemployment rate (e.g. Lin, 2008; Öster and Agell, 2007; Raphael and Winter-Ebmer, 2001). However, given the absence of any external instruments and the dynamic model specification of Eq. 1, a system-GMM estimator is applied instead (Arellano and Bover, 1995; Blundel and Bond, 1998). This technique has been used in other crime-related studies (e.g. Goulas and Zervoyianni, 2013; 2015; Saridakis and Spengler, 2012) and its advantage relies on using appropriately lagged levels and lagged differences of the explanatory variables as instruments so that causation will only run from the right to the lefthand side of Eq. 1. Under mild stationarity assumptions, this estimator mitigates the small sample bias, the presence of endogeneity in dynamic panel data models and the high persistency in the series (Soto, 2009). Due to the relatively small sample size, the instrument matrix is collapsed in order to avoid the problem of instrument proliferation that may lead to suspiciously high pass rates of specification tests (Roodman, 2009a; 2009b). The appropriateness of the model specification is examined through standard tests for second order autocorrelation in the generated residuals and the validity of the over-identifying restrictions. 


\section{Data}

In order to perform the empirical exploration of the main working hypothesis, three datasets have been linked together. The first one is available from the Hellenic Statistical Authority (EL.STAT) and provides data regarding the criminal activity for a number of categories by region and year for the period 1999-2013. The regional units are ten aggregated areas that follow closely the NUTS-2 classification. ${ }^{1}$ Five crime categories are considered here. The first one is the rate of the total criminal activity. The rest ones concern rates of crimes against life, against property, against personal freedom and drugs-related ones. ${ }^{2}$ Data regarding the male unemployment rate by region are provided by the Hellenic Statistical Authority (EL.STAT). Data regarding the long-term unemployment and the various economic and demographic characteristics (population density, share of males, share of those aged 15-39 years old, share of foreigners, share of those who only attended primary schooling and the regional 90th/10th ratio of the composition corrected individual gross hourly wage distribution) have been collected from the Greek and the European Labour Force Surveys. The information contained in these datasets was used to construct a regional panel dataset that consists of 10 aggregated regions observed over the period 1999-2013. Table 1 displays some basic descriptive statistics for the variables used in the empirical analysis.

Table 1. Basic descriptive statistics.

\begin{tabular}{|c|c|c|c|c|c|}
\hline Variable & Mean & Std. Dev. & Min. & $\operatorname{Max}$. & Obs. \\
\hline Male unemployment rate & 12.70 & 5.37 & 5.27 & 30.90 & 150 \\
\hline Long-term unemployment rate & 6.61 & 4.04 & 1.5 & 20.7 & 150 \\
\hline Rate of total criminal activity & 3364.8 & 1711.6 & 642.5 & 8898.5 & 150 \\
\hline Rate of crimes against life & 13.23 & 6.84 & 2.42 & 40.97 & 150 \\
\hline Rate of crimes against property & 503.14 & 366.78 & 60.20 & 1760.15 & 150 \\
\hline Rate of crimes against personal freedom & 65.93 & 43.39 & 15.45 & 224.59 & 150 \\
\hline Rate of crimes related to drugs & 81.54 & 31.77 & 0 & 190.09 & 150 \\
\hline Population density & 156.44 & 297.58 & 35.65 & 1080.35 & 150 \\
\hline Share of males & 49.91 & 0.87 & 48.20 & 51.74 & 150 \\
\hline Share of those aged $15-39$ years old & 34.45 & 2.07 & 29.78 & 39.03 & 150 \\
\hline Share of foreigners & 4.66 & 2.07 & 1.24 & 11.03 & 150 \\
\hline Share of those with only primary schooling & 83.33 & 5.95 & 63.73 & 92.95 & 150 \\
\hline p90/p10 ratio of individual hourly wages & 1.69 & 0.12 & 1.46 & 2.01 & 150 \\
\hline
\end{tabular}

Source: Hellenic Statistical Authority (EL.STAT), Greek Labour Force Survey (LFS), European Labour Force Survey (ELFS).

Note: The criminal activity rates have been calculated as the number of recorded crimes per 100,000 residents.

\section{Results}

Tables 2 and 3 display the results regarding the effects of male and long-term unemployment on various types of criminal activity, respectively. The estimated models are considered to be statistically adequate when there is no second order autocorrelation in the residuals and when the over-identifying restrictions are not rejected. The upper panel of each table presents the results obtained using the Within estimator and the lower panel those obtained after applying the system-GMM one. Regarding the former, the reported $t$-statistics have been calculated using robust standard errors clustered by region. Regional and time dummies were highly jointly

\footnotetext{
${ }^{1}$ Namely, these are Attica, Central Greece, Peloponnese, Ionian Islands, Epirus, Thessaly, Aegean Islands, Crete, Macedonia and Thrace.

${ }^{2}$ Crimes against personal freedom is a type not often examined in the literature and it includes activities like abduction, vigilantism, threatening, abuse, domestic violence, trafficking etc.
} 
significant across different models, justifying their inclusion into the crime equations. Also the regional time trend was statistically significant and positive for every type of criminal activity except from crimes against life where it was negative. For the system-GMM estimates, the Sargan test fails to reject the null hypothesis about the validity of the over-identifying restrictions in every model. The reported $p$-values for the Arrelano-Bond serial correlation tests indicate the presence of a significant first order autocorrelation for the disturbances in the firstdifferenced equation, but reject the existence of second order autocorrelation. Overall, the model specification is being supported by the results of these tests.

Table 2. Crime and male unemployment in Greece, 1999-2013.

\begin{tabular}{|c|c|c|c|c|c|}
\hline \multirow{2}{*}{ Dependent variable } & \multicolumn{5}{|c|}{ Panel A: Within (LSDV) estimates } \\
\hline & Total & Life & Property & Freedom & Drugs \\
\hline $\log U_{r t}$ & $-.002(-.040)$ & $.209(2.30)^{\mathrm{b}}$ & $.032(.030)$ & $.195(2.30)^{\mathrm{b}}$ & $-.032(-.460)$ \\
\hline $\log U_{r t} \times$ post-2009 period & $.332(1.89)^{\mathrm{b}}$ & $-.770(-2.02)^{\mathrm{b}}$ & $.098(.460)$ & $.222(.880)$ & $.263(1.40)$ \\
\hline $\log$ Crime $_{r t-1}$ & $.653(7.49)^{\mathrm{a}}$ & $.268(2.01)^{\mathrm{c}}$ & $.720(19.40)^{\mathrm{a}}$ & $.357(2.13)^{\mathrm{c}}$ & $.597(6.16)^{\mathrm{a}}$ \\
\hline$R$-squared & .961 & .840 & .967 & .923 & .860 \\
\hline$F$-test (Region) & .000 & .000 & .000 & .000 & .000 \\
\hline \multirow[t]{3}{*}{$F$-test (Year) } & .000 & .237 & .000 & .000 & .001 \\
\hline & \multicolumn{5}{|c|}{ Panel B: System-GMM estimates } \\
\hline & Total & Life & Property & Freedom & Drugs \\
\hline $\log U_{r t}$ & $-.070(-.890)$ & $.120(.760)$ & $-.033(-.270)$ & $.100(1.68)^{\mathrm{c}}$ & $-.117(-1.56)$ \\
\hline $\log U_{r t} \times$ post-2009 period & $.544(2.53)^{\mathrm{b}}$ & $-.725(-1.98)^{\mathrm{a}}$ & $.106(.460)$ & $.460(2.01)^{\mathrm{b}}$ & $.384(2.49)^{\mathrm{b}}$ \\
\hline $\log$ Crime $_{r t-1}$ & $.547(8.07)^{\mathrm{a}}$ & $.187(1.40)$ & $.713(32.59)^{\mathrm{a}}$ & $.322(1.83)^{\mathrm{c}}$ & $.627(7.22)^{\mathrm{a}}$ \\
\hline Sargan test & .312 & .310 & .311 & .262 & .268 \\
\hline $\mathrm{AR}(1)$ test & .014 & .009 & .008 & .016 & .039 \\
\hline $\mathrm{AR}(2)$ test & .406 & .189 & .647 & .251 & .628 \\
\hline Instruments & 45 & 45 & 45 & 45 & 45 \\
\hline "Regional characteristics/trend & Yes & Yes & Yes & Yes & Yes \\
\hline Region fixed effects & Yes & Yes & Yes & Yes & Yes \\
\hline Year fixed effects & Yes & Yes & Yes & Yes & Yes \\
\hline Observations & 140 & 140 & 140 & 140 & 140 \\
\hline
\end{tabular}

Source: Hellenic Statistical Authority (EL.STAT), Greek Labour Force Survey (LFS), European Labour Force Survey (ELFS).

Note: $\mathrm{t}$-statistics in parentheses. a, b and $\mathrm{c}$ denote statistical significance at the $1 \%, 5 \%$ and $10 \%$ levels, respectively. For the various statistical tests, the p-values are reported.

According to the results, the effect of male unemployment is positive and statistically significant only after 2009 for the total criminal activity as well as for crimes against personal freedom and crimes related to drugs. Long-term unemployment exerts a lower impact only on the total criminal activity after 2009. This may be an indication of the operation of a weaker motivational effect for the long-term unemployed who are also more likely to collect state unemployment benefits. In accordance to evidence reported in previous research (Cook and Zarkin, 1985; Raphael and Winter-Ebmer, 2001) crimes against life are negatively related to male unemployment rate after 2009 and they seem to be weakly persistent over time. The absence of a significant relationship between unemployment and property-related crimes even after 2009 seems striking, however, it displays the greatest degree of persistence, perhaps reflecting the existence of strong peer effects at the regional level. Dynamics are also important for the total criminal activity, crimes against personal freedom and crimes related to drugs. Although not reported here, the inclusion of the lagged dependent variable into the explanatory vector always reduced the magnitude of the estimated coefficients of the interaction term. The rest of the explanatory variables have their own interpretation although not discussed in detail here due to space limitations. It should be mentioned though that the share of foreigners always entered with a negative sign while the effect of the wage inequality measure was not found to 
be statistically significant. The regional shares of male population and those with only primary schooling enter with a positive sign and they are statistically significant. Alternative regional income-related variables (i.e. the regional GDP, the 10th and the 25th percentiles of the composition corrected hourly wage distribution) and their lags have also been used in order to check the robustness of the results, however, the results remained unaltered. The one-year lag of the unemployment rate was also found not to exert a significant effect on crime activity. Overall, the results do not support the existence of an overall strong relationship between criminal activity and the prevailing labour market conditions in Greece during the period under examination. However, a U-C relationship seems to be uncovered for the period during the debt crisis. It should be noticed though that the reported results should be interpreted with some caution given the short time dimension of the dataset, the level of aggregation and limitations regarding the availability of some variables that could have also been used in the analysis.

Table 3. Crime and long-term unemployment in Greece, 1999-2013.

\begin{tabular}{|c|c|c|c|c|c|}
\hline \multirow{2}{*}{ Dependent variable } & \multicolumn{5}{|c|}{ Panel A: Within (LSDV) estimates } \\
\hline & Total & Life & Property & Freedom & Drugs \\
\hline $\log U_{r t}$ & $-.007(-.090)$ & $.037(.290)$ & $-.053(-.670)$ & $-.001(-.010)$ & $-.006(-.080)$ \\
\hline $\log U_{r t} \times$ post-2009 period & $.134(1.61)$ & $-.302(-1.74)$ & $-.030(.390)$ & $.038(.210)$ & $-.050(-.380)$ \\
\hline $\log$ Crime $_{r t-1}$ & $.697(8.00)^{\mathrm{a}}$ & $.286(2.33)^{\mathrm{b}}$ & $.726(16.44)^{\mathrm{a}}$ & $.419(2.51)^{\mathrm{b}}$ & $.587(6.63)^{\mathrm{a}}$ \\
\hline$R$-squared & .960 & .835 & .967 & .918 & .857 \\
\hline$F$-test (Region) & .000 & .001 & .000 & .000 & .000 \\
\hline \multirow[t]{3}{*}{$F$-test (Year) } & .000 & .385 & .000 & .000 & .000 \\
\hline & \multicolumn{5}{|c|}{ Panel B: System-GMM estimates } \\
\hline & Total & Life & Property & Freedom & Drugs \\
\hline $\log U_{r t}$ & $-.071(-.850)$ & $-.114(-.960)$ & $-.119(-1.70)^{\mathrm{c}}$ & $-.071(-.850)$ & $-.073(-1.04)$ \\
\hline $\log U_{r t} \times$ post-2009 period & $.253(2.04)^{\mathrm{b}}$ & $-.379(-1.99)^{b}$ & $.108(.640)$ & $.168(1.03)$ & $.004(.030)$ \\
\hline $\log$ Crime $_{r t-1}$ & $.577(7.17)^{\mathrm{a}}$ & $.185(1.55)$ & $.699(25.27)^{\mathrm{a}}$ & $.370(2.08)^{\mathrm{b}}$ & $.611(7.14)^{\mathrm{a}}$ \\
\hline Sargan test & .355 & .419 & .338 & .300 & .208 \\
\hline $\mathrm{AR}(1)$ test & .012 & .008 & .007 & .011 & .038 \\
\hline $\mathrm{AR}(2)$ test & .969 & .251 & .503 & .152 & .465 \\
\hline Instruments & 45 & 45 & 45 & 45 & 45 \\
\hline Regional characteristics/trend & Yes & Yes & Yes & Yes & Yes \\
\hline Region fixed effects & Yes & Yes & Yes & Yes & Yes \\
\hline Year fixed effects & Yes & Yes & Yes & Yes & Yes \\
\hline Observations & 140 & 140 & 140 & 140 & 140 \\
\hline
\end{tabular}

Source: Hellenic Statistical Authority (EL.STAT), Greek Labour Force Survey (LFS), European Labour Force Survey (ELFS).

Note: $\mathrm{t}$-statistics in parentheses. a, b and $\mathrm{c}$ denote statistical significance at the $1 \%, 5 \%$ and $10 \%$ levels, respectively. For the various statistical tests, the p-values are reported.

\section{Concluding remarks}

This paper attempted a first investigation of the unemployment-crime relationship in Greece during the period 1999-2013 using panel data at the regional level. For certain crime categories, namely the total criminal activity, crimes against personal freedom and crimes related to drugs, the results support the operation of a positive association with the male unemployment rate but only after 2009. Long-term unemployment seems to exert a positive but much weaker impact only on total criminal activity during the crisis years. For the same period, crimes against life seem to be negatively linked to the prevailing labour market conditions. Finally, regional criminal activity exhibits a significant degree of inertia in most of the cases indicating the need for taking dynamics into consideration when studying the relationship between crime and unemployment. However, these first evidence should be interpreted with caution given the aggregation level and data limitations. 


\section{References}

Arellano, M. and Bover, O. (1995) Another look at the instrumental variable estimation of error-components models, Journal of Econometrics, 68(1), 29-51.

Arvanites, T.M. and Defina, R.H. (2006) Business cycles and street crime, Criminology, 44(1), 139-164.

Becker, G. (1968) Crime and punishment: An economic approach, Journal of Political Economy, 76(2), 169-217.

Blundell, R. and Bond, S. (1998) Initial conditions and moment restrictions in dynamic panel data models, Journal of Econometrics, 87(1), 115-143.

Cantor, D. and Land, K.C. (1985) Unemployment and crime rates in the Post-World War II in the United States: A theoretical and empirical analysis, American Sociological Review, 50, 317-322.

Carmichael, F. and Ward, R. (2001) Male unemployment and crime in England and Wales, Economics Letters, 73, 111-115.

Cook, P.J. and Zarkin, G.A. (1985) Crime and the business cycle, Journal of Legal Studies, 14(1), 115-128.

Freeman, R. (1999) The economics of crime, Orley Ashenfelter and David Card (ed.), Handbook of Labor Economics, 3, 3529-3563, Amsterdam: North Holland.

Goulas, E. and Zervoyianni, A. (2013) Economic growth and crime: Does uncertainty matter?, Applied Economics Letters, 20, 420-427.

Goulas, E. and Zervoyianni, A. (2015) Economic growth and crime: Is there an asymmetric relationship?, Economic Modelling, 49, 286-295.

Kleck, G. and Chiricos, T. (2002) Unemployment and property crime: A target-specific assessment of opportunity and motivation as mediating factors, Criminology, 40(3), 649-679.

Lin, M.J. (2008) Does unemployment increase with crime? Evidence from U.S. data 19742000, Journal of Human Resources, 43(2), 413-436.

Machin, S. and Manning, A. (1999) The causes and consequences of long-term unemployment in Europe, Orley Ashenfelter and David Card (ed.), Handbook of Labor Economics, 3, 3085-3139, Amsterdam: North Holland.

Machin, S. and Meghir, C. (2004) Crime and economic incentives, Journal of Human Resources, 34(4), 958-979.

Öster, A. and Agell, J. (2007) Crime and unemployment in turbulent times, Journal of the European Economic Association, 5(4), 752-775.

Phillips, J. and Land, K.C. (2012) The link between unemployment and crime rate fluctuations: An analysis at the county, state and national levels, Social Science Research, 41, 681694.

Raphael, S. and Winter-Ebmer, R. (2001) Identifying the effect of unemployment on crime, Journal of Law and Economics, 44(1), 259-283.

Saridakis, G. and Spengler, H. (2012) Crime, deterrence and unemployment in Greece: A panel data approach, Social Science Journal, 49(2), 167-174.

Soto, M. (2009) System GMM estimation with a small sample, Working Paper, Institute for Economic Analysis, Barcelona.

Witt, R., Clarke, A. and Fielding, N. (1998) Crime, earnigns inequality and unemployment in England and Wales, Applied Economics Letters, 5, 265-267. 